\title{
Hydroxybenzoic Acids - A Study of Their Electronic Spectra, Structure and Reactivity
}

\author{
K. P. Krishnan Namboodiri and S. Viswanathan \\ Department of Physical Chemistry, University of Madras, India \\ V. C. Jyothi Bhasu * \\ Department of Inorganic and Physical Chemistry, Indian Institute of Science, Bangalore, India
}

Z. Naturforsch. 37 a, 1185-1192 (1982); received May 26, 1982

\begin{abstract}
The three isomeric hydroxybenzoic acids were subjected to all-valence-electron CNDO/2 calculations. The $\sigma$-core charges from these calculations and subsequently revised valence-state ionization potentials and one-centre two-electron integrals were used in Pariser-Parr-Pople (PPP) CI calculations for the title compounds following the Nishimoto-Forster scheme to explain their electronic spectra. The spectra were all recorded in aqueous media. The results from the CNDO/2 calculations were used to obtain useful electronic structural parameters and to study the chemical reactivity of these molecules. All the results were compared with the basic compounds, namely phenol and benzoic acid.
\end{abstract}

\section{Introduction}

Among the hydroxybenzoic acids, the ortho isomer seems to have been studied quite extensively from both the experimental and theoretical point of view $[1-5]$. However due attention was persistently lacking in the case of the other two isomers except a recent work [6]. Attempts have been made to explain the electronic spectra of substituted benzene derivatives using semiempirical SCF LCAOMO Pariser-Parr-Pople (PPP) method [7]. However similar studies on disubstituted benzene derivatives containing both electron withdrawing and electron releasing groups are limited [8]. Hydroxy benzoic acids belong to this class.

The electronic spectra of different isomers of hydroxy benzoic acids have been reported by various authors $[4,5]$. However no attempts have been made so far to assign the electronic transitions quantitatively. In the electronic spectral analysis of nitrobenzene by Gordon and Neumer [8] a new dimension has been given to the conventional PPP method [7]. The data on $\sigma$-charges obtained from $\mathrm{CNDO} / 2$ and $\mathrm{ab}$ initio calculations were used successfully in the PPP-CI studies of nitrophenols and cresols $[9,10]$.

The effect of substituents on various physical properties and reactivities of organic molecules has

\footnotetext{
* Present address: Donnan Laboratories, University of Liverpool, L69 3BX, England.

Reprint requests to Herrn K. P. Krishnan Namboodiri, Department of Physical Chemistry, University of Madras, Madras - 600025/Indien.
}

been discussed extensively in recent years. Substituent effects arise due to two reasons-electronic and steric. A knowledge of the electronic structure is vital in order to explain the electronic component of the substituent effects of the concerned molecule. In this context semi-empirical quantum chemical methods play a useful role. In the electronic structure studies the CNDO/2 method has been used in combination with ab initio calculations [11-19]. The electronic structural parameters available from CNDO/2 calculations for the type of molecules treated here have been demonstrated to be quite reliable and comparable to ab initio results [20]. Another reason for taking up the present study is that in an earlier work [21] on the benzoate ion it was indicated that both the carboxylate and carbonyl groups would behave identically as far as their orientation effects are considered. In this paper light is thrown on the actual state of affairs. We are reporting the results of $\mathrm{CNDO} / 2, \mathrm{CNDO} / 2$ based PPP-CI and conventional PPP-CI calculations on the three isomeric hydroxybenzoic acids along with their basic molecules, namely benzoic acid, phenol and the benzoate ion.

\section{Method of Calculations}

For the CNDO/2 calculations the standard program [22] was used. For PPP-CI calculations a program written by the authors in Fortran IV was employed. The geometry of these molecules for PPP-CI and CNDO/2 calculations was based mainly 
on the recent X-ray reports (vide Figure 2). How. ever the bond lengths and bond angles in the phenyl part of these molecules have been taken to be uniformly constant. In case of the benzoate ion, the two carbon-oxygen bonds have been considered to be of the same length namely the average of the $-\mathrm{C}=\mathrm{O}$ and $-\mathrm{C}(\mathrm{C})-\mathrm{OH}$ bonds.

The PPP-CI procedure adopted here is identical to that used in our earlier works [8]. Again instead of the integral $\sigma$-core charges (conventionally used in PPP method), more realistic ones deduced from the all valence electron $\mathrm{CNDO} / 2$ were employed. The new $\sigma$-core changes (Fig. 1) are evidently different from those one would have chosen in conventional PPP method. Since we were interested in the anions of these isomeric hydroxybenzoic acids, the $\sigma$-charges available from the $\mathrm{CNDO} / 2$ were judiciously modified for the carboxylate group. The improvements obtained in the final results will become evident when the conventional PPP and the modified PPP results are compared later on.

The PPP-CI procedure employs the Nishimoto and Forster parameter scheme $[13,23]$, which is found to be capable of reproducing spectral maxima and the relative intensities of mono- and poly-substituted benzene derivatives. For the two electron one center repulsion integral, we have used the formula suggested by Nishimoto and Mataga [24]. The $\beta$-resonance integrals were transferred from similar molecules [13] and then modified by taking into account the $\pi$-bond orders available from our $\mathrm{CNDO} / 2$ results.

The valence-state ionisation potentials as well as the two electron-one-center repulsion integrals for the various atoms of non-integer $\sigma$-core charges were obtained by linear interpolation of the corresponding +1 and +2 parameters given by Nishimoto and Forster [13]. The $\pi$-electron parameters for the carbon atoms were derived similarly by using $\mathrm{C}^{+2}$ values given by Dewar and Morita [25]. All the $\pi$-electron parameters used here are summarised in Table 1.

\section{Experimental}

The three isomeric hydroxy benzoic acids (Analar, BDH) were used after recrystallisation [26].

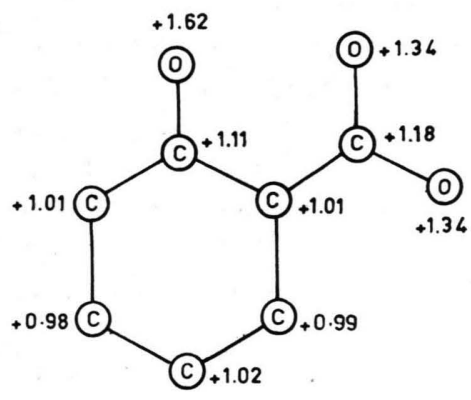

or tho-HYDROXYBENZOATE ION

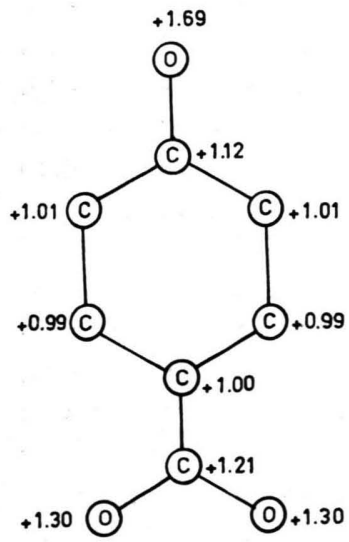

Para-HYDROXYBENZOATE ION

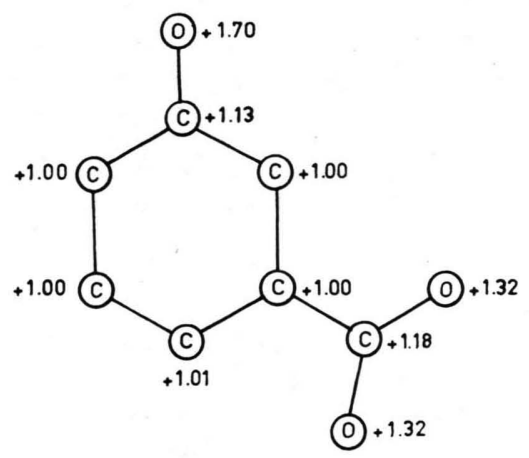

meta-HYDROXYBENZOATE ION

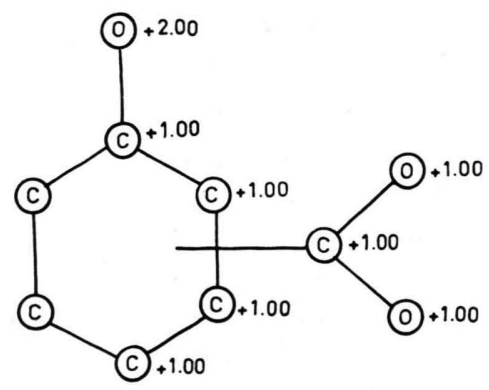

Commonly assumed hydroxybenzoate ion $\sigma$-core charges for PPP-calculations.
Fig. 1. Proposed $\sigma$-core charges for the three isomers of hydroxybenzoate ion based on $\mathrm{CNDO} / 2$ study. 
Table 1. $\pi$-electron Parameter summary for PPP-CI calculations.

\begin{tabular}{|c|c|c|}
\hline $\begin{array}{l}\text { Atom } \\
\text { ( } \sigma \text {-corecharge) }\end{array}$ & $\begin{array}{l}\text { Valance state } \\
\text { ionisation } \\
\text { energy eV }\end{array}$ & $\begin{array}{l}\text { One-centre } \\
\text { repulsion } \\
\text { integral } \gamma_{\mu \mu}, \mathrm{eV}\end{array}$ \\
\hline $\mathrm{C}(+0.98)$ & -10.912 & 11.020 \\
\hline $\mathrm{C}(+0.99)$ & -11.036 & 11.075 \\
\hline $\mathrm{C}(+1.01)$ & -11.280 & 11.190 \\
\hline $\mathrm{C}(+1.02)$ & -11.410 & 11.240 \\
\hline $\mathrm{C}(+1.11)$ & -12.520 & 11.740 \\
\hline $\mathrm{C}(+1.12)$ & -12.650 & 11.790 \\
\hline $\mathrm{C}(+1.13)$ & -12.770 & 11.850 \\
\hline $\mathrm{C}(+1.18)$ & -13.390 & 12.120 \\
\hline $\mathrm{C}(+1.21)$ & -13.760 & 12.290 \\
\hline$O(1.0)$ & -17.70 & 15.23 \\
\hline $\mathrm{O}(1.30)$ & -22.34 & 17.16 \\
\hline $\mathrm{O}(1.32)$ & -22.49 & 17.22 \\
\hline $\mathrm{O}(1.34)$ & -22.79 & 17.15 \\
\hline $\mathrm{O}(1.62)$ & -27.12 & 19.14 \\
\hline $\mathrm{O}(1.69)$ & -28.19 & 19.58 \\
\hline O (1.70) & -28.34 & 19.64 \\
\hline $\mathrm{O}(2.0)$ & -32.90 & 21.53 \\
\hline
\end{tabular}

$\beta$ Resonance Integrals; eV

$$
\begin{aligned}
& \beta \mathrm{C}-\mathrm{OH}=-1.800 \quad \beta \mathrm{C}-\mathrm{CO}_{2} \mathrm{H}=-2.000 \\
& \beta \mathrm{C}-\mathrm{C}=-2.386 \quad \beta \mathrm{C}_{\mathrm{O}}^{\mathrm{O}^{2}}(-)=-2.450
\end{aligned}
$$

Conductivity water was used in preparing the solutions. The solutions prepared were protected by black cloth to avoid any photochemical reaction.

\section{Results and Discussion}

\section{Electronic structure and reactivity:}

The electron density distribution $(\pi$ and $\sigma$ ) and net charges on each atom of the three isomeric hydroxybenzoic acids coupled with their basic molecules (phenol, benzoic acid and benzoate ion) are given in Table 2. Numbering convention and geometry used are in Figure 2. The net charges (Tables 2 and 3 ) and $\pi$-bond orders (Table 4) calculated with the CNDO/2 and PPP methods for hydroxybenzoic acids are in good agreement.

The carboxyl group, when attached to a phenyl ring, has been known to be electron withdrawing and hence meta directing. The electron donating and consequent ortho-para directing capacities of the hydroxyl group have been well settled. The interplay of these two groups, when attached at different positions relative to each other on an aromatic nucleus, may lead to some interesting electronic, structural features. The following brief discussion is centered on these lines.
A hydroxyl group attached to a benzene nucleus is ortho-para directing. The results in Table 2 on phenol substantiate this fact. The positions ortho and para to hydroxyl group $\left(\mathrm{C}_{2}, \mathrm{C}_{6}\right.$ and $\mathrm{C}_{4}$ in Fig. 2) are rich in $\pi$-electron density and bear net negative charges. These results are in agreement with the $a b$ initio calculations published elsewhere [19].

A carboxyl group attached to a benzene nucleus is meta orienting. The results in Table 2 on benzoic acid clearly corroborate this fact. The positions meta to carboxyl group $\left(\mathrm{C}_{3}\right.$ and $\mathrm{C}_{5}$ in Fig. 2) are rich in $\pi$-electron density and bear less positive charges compared to the other positions. These results also agree with the $a b$ initio calculations available [19]. Product analysis also illustrates this.

Moser [21] in an early M. Ö. method obtained the charge densities of benzoate ion species to be meta $>$ ortho $>$ para and compared these values with the experimentally obtained isomer distribution for nitration of benzoic acid. Of the several methods employed in his study he found that the results obtained from only one of his methods tallied. Now, employing the $\mathrm{CNDO} / 2$ calculations we have found that this is not the case. Actually, the $\pi$-electron population of various positions of benzoate ion indicates the order to be $p>m>o$ (Table 2). The reason is that the charged substituent appears to polarise the entire $\pi$-system, so that the $\pi$-charge changes gradually as the distance from the $-\mathrm{COO}^{(-)}$increases; this polarisation effect dominates over any contribution from the $\pi$-inductive and mesomeric effects.

In ortho-hydroxybenzoic acid (salicylic acid) molecule the directing properties of the two substituents $(\mathrm{OH}$ and $\mathrm{COOH}$ groups) reinforced each other. As a result of this the positions $\mathrm{C}_{4}$ and $\mathrm{C}_{6}$ (ortho-meta to hydroxyl and para-meta to carboxyl respectively) possess excess $\pi$-electron density and bear net negative charges definitely higher than those found in identical positions in phenol and benzoic acid molecules. The positions $\mathrm{C}_{3}$ and $\mathrm{C}_{5}$ (meta to hydroxyl and ortho-para to carboxyl respectively) are, as expected, deficient in $\pi$-electron density. The total $\pi$-donation to the molecule as a whole is -0.017 e.s.u. which is less compared to phenol $(-0.57)$ but more than benzoic acid (0.039). From the reactivity point of view the positions $\mathrm{C}_{4}$ and $\mathrm{C}_{6}$ may be readily available for aromatic electrophilic attack and $\mathrm{C}_{3}$ and $\mathrm{C}_{5}$ for 
Table 2. Electron population and net charge data for phenol, benzoic acid, benzoate ion and hydroxy benzoic acids by CNDO/2 calculation.



* The numbering of the atoms is given in Figure 2 .

aromatic nucleophilic attack. It is known that, among the three isomeric hydroxybenzoic acids, only ortho isomer exhibits strong intramolecular hydrogen bonding - a piece of work which has been studied extensively [1,2 and 3]. Our present calculation also supports this view accounting the difference in charges found on the hydroxyl hydrogen $\left(\mathrm{H}_{17}\right)$ and carboxyl oxygen $\left(\mathrm{O}_{8}\right)$ atoms compared to meta and para isomers (Fig. 2 and Table 2).

In meta hydroxybenzoic acid the orienting effects of the carboxyl and hydroxyl groups do not superimpose. Our calculations show that (Table 2) the 


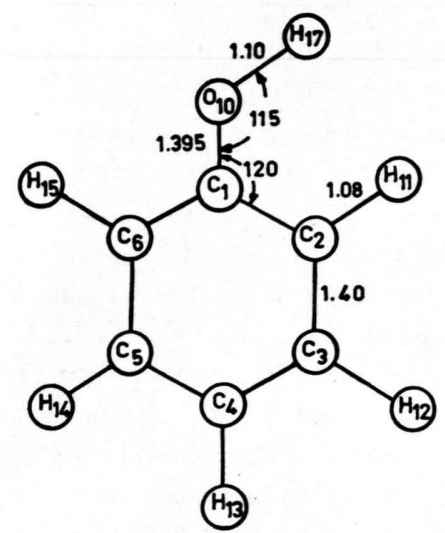

PHENOL

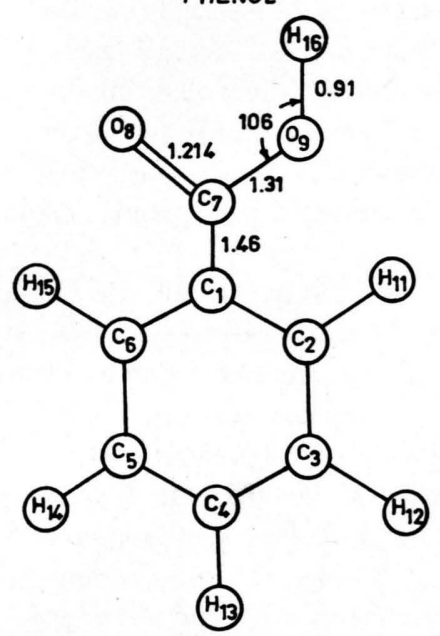

BENZOIC ACID

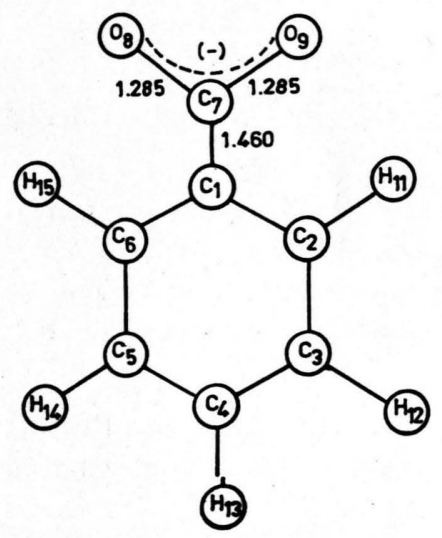

BENZOATE ION

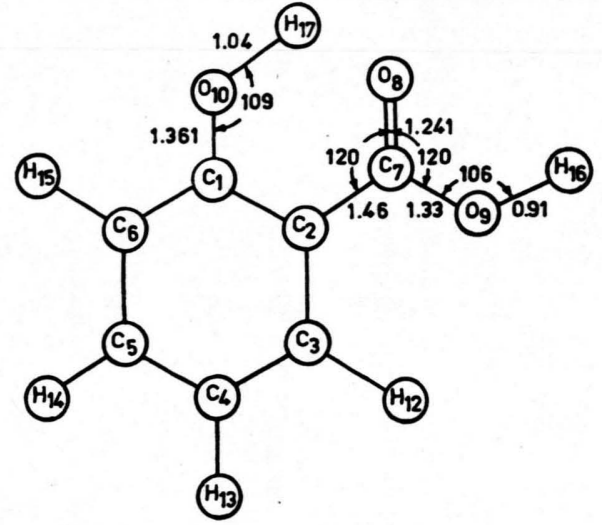

ortho-HYDROXYBENZOIC ACID

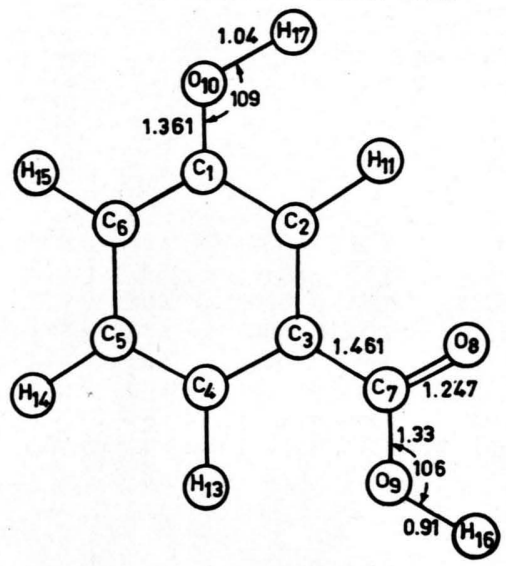

meta-HYDROXYBENZOIC ACID

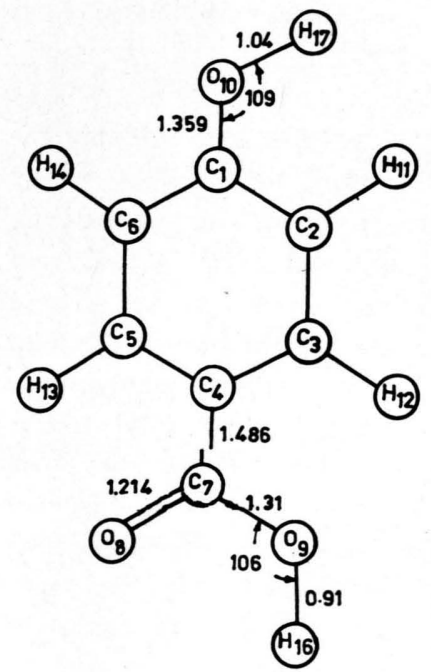

Para-HYDROXYBENZOIC ACID

Fig. 2. Idealised geometry and numbering convention used for phenol, benzoic acid, benzoate ion and hydroxybenzoic acid calculations*.

* Data based on (i) Acta. Cryst. 6, 260 (1953); (ii) ibid. 8, 157 (1955); (iii) Bull. Chem. Soc. Japan. 46, 804 (1973). 
Table 3. Calculated net charges from PPP-CI study for Hydroxy Benzoic Acids.

\begin{tabular}{|c|c|c|c|}
\hline \multirow[t]{2}{*}{ Atoms } & \multicolumn{3}{|c|}{ Hydroxy benzoic acid } \\
\hline & Ortho & Meta & Para \\
\hline $\mathrm{C}_{1}$ & 0.082 & 0.18 & 0.172 \\
\hline $\mathrm{C}_{2}$ & -0.083 & -0.006 & -0.043 \\
\hline $\mathrm{C}_{3}$ & 0.08 & 0.001 & 0.015 \\
\hline $\mathrm{C}_{4}$ & -0.043 & -0.035 & -0.049 \\
\hline $\mathrm{C}_{5}$ & 0.00 & 0.010 & 0.312 \\
\hline $\mathrm{C}_{6}$ & -0.032 & -0.050 & -0.039 \\
\hline $\mathrm{C}_{7}$ & 0.460 & 0.48 & 0.532 \\
\hline $\mathrm{O}_{8}$ & -0.376 & -0.407 & -0.393 \\
\hline $\mathrm{O}_{9}$ & -0.324 & -0.33 & -0.362 \\
\hline $\mathrm{O}_{10}$ & -0.27 & -0.186 & -0.214 \\
\hline
\end{tabular}

Table 4. Calculated $\pi$-bond orders by $\mathrm{CNDO} / 2$ method.

\begin{tabular}{llll}
\hline Bond & \multicolumn{2}{l}{ Hydro benzoic acids } \\
\cline { 2 - 4 } & Ortho & Meta & Para \\
\hline $\mathrm{C}_{1}-\mathrm{C}_{2}$ & $0.636(0.620)$ & $0.649(0.651)$ & $0.635(0.638)$ \\
$\mathrm{C}_{2}-\mathrm{C}_{3}$ & $0.626(0.643)$ & $0.639(0.640)$ & $0.679(0.679)$ \\
$\mathrm{C}_{3}-\mathrm{C}_{4}$ & $0.648(0.672)$ & $0.635(0.640)$ & $0.636(0.638)$ \\
$\mathrm{C}_{4}-\mathrm{C}_{5}$ & $0.682(0.657)$ & $0.669(0.666)$ & $0.635(0.638)$ \\
$\mathrm{C}_{5}-\mathrm{C}_{6}$ & $0.626(0.670)$ & $0.667(0.670)$ & $0.680(0.679)$ \\
$\mathrm{C}_{6}-\mathrm{C}_{7}$ & $0.602(0.645)$ & $0.638(0.637)$ & $0.635(0.638)$ \\
$\mathrm{C}_{7}-\mathrm{O}_{8}$ & $0.829(0.764)$ & $0.860(0.786)$ & $0.830(0.765)$ \\
$\mathrm{C}_{7}-\mathrm{O}_{9}$ & $0.370(0.392)$ & $0.354(0.464)$ & $0.431(0.393)$ \\
$\mathrm{C}_{1}-\mathrm{O}_{10}$ & $0.307(0.259)$ & $0.262(0.263)$ & $0.276(0.257)$ \\
$\mathrm{C}_{2}-\mathrm{C}_{7}$ & & & \\
or & & & \\
$\mathrm{C}_{3}-\mathrm{C}_{7}$ & $0.318(0.272)$ & $0.290(0.274)$ & $0.270(0.269)$ \\
or & & & \\
$\mathrm{C}_{4}-\mathrm{C}_{7}$ & & & \\
\cline { 2 - 4 }
\end{tabular}

Note: The values given in parantheses refer to bond orders calculated from the modified PPP-CI Method.

positions $\mathrm{C}_{2}, \mathrm{C}_{4}$ and $\mathrm{C}_{6}$, ortho-para to both the hydroxyl and carboxyl groups, have excess $\pi$-electrons and bear negative charges. The position $\mathrm{C}_{5}$ (meta to both carboxyl and hydroxyl) is positively charged showing depletion of $\pi$-electrons. These results show that the influence of the hydroxyl group is more pronounced than that of the carboxyl group. This is also borne by the fact that the total $\pi$-electron donation is found to be -0.027 esu. This value is more negative than the ortho isomer $(-0.017 \mathrm{esu})$ where the ortho-para directing effect of the hydroxyl group is aligned with the meta effect (electron withdrawing effect) of carboxyl group. The electron withdrawing effect of carboxyl group is much pronounced at $\mathrm{C}_{4}$, which hence bears least negative charge. Considering reactivity, the positions $\mathrm{C}_{2}, \mathrm{C}_{5}$ and $\mathrm{C}_{4}$ are available for elctro- philic attack in the descending order. Of course, the position $\mathrm{C}_{5}$ naturally prefers nucleophilic attack.

The reinforced orienting effects of the hydroxyl and carboxyl groups do operate in para isomer like ortho isomer. Consequently, the positions $\mathrm{C}_{2}$ and $\mathrm{C}_{6}$ (ortho to hydroxyl and meta to carboxyl) are rich in $\pi$-electron density and show a net negative charge (Table 2). The positions $\mathrm{C}_{3}$ and $\mathrm{C}_{5}$ (ortho to carboxyl and meta to hydroxyl) are deficient in $\pi$-electron density and bear net $(+)-$ ve charges. The total $\pi$-electron accession to the phenyl ring is found to be -0.031 esu which is most negative among the three isomers. Thus in para isomer polarization of the $\pi$-electrons of the ring, is more efficient (compared to both ortho \& meta forms) in relaying the dipolar nature of the substitutents to the reaction centre. As far as reactivity is concerned the positions $\mathrm{C}_{2}$ and $\mathrm{C}_{6}$ are obviously prone to aromatic electrophilic attack and $\mathrm{C}_{3}$ and $\mathrm{C}_{5}$ for aromatic nucleophilic attack.

A comparison of the reactivity of all the three isomers, based on the electronic structure, reveals that the para isomer is most reactive to an electrophilic attack. This is so because, only in the para isomer, the ortho positions of hydroxyl group are farthest from the carboxyl group. In fact, the ortho-positions $\left(\mathrm{C}_{2}\right.$ and $\left.\mathrm{C}_{6}\right)$ of the para isomer and the para position $\left(\mathrm{C}_{4}\right)$ of the ortho isomer appear to be more reactive than the corresponding positions in the basic phenol itself.

\section{Electronic Spectra - An Analysis}

Table 5 contains the following spectral results of isomeric hydroxybenzoic acids.

(a) The conventional PPP-CI results on transitional energies for the completely ionised molecules $\left(\lambda_{\max }^{\mathrm{nm}}\right)$ and the corresponding intensities $(\log \varepsilon)-$ which is calculated from the oscillator strength (cf. 9. C).

(b) The CNDO/2 based or modified, PPP-CI results on transitional energies and their internsities, again for the ionised molecules.

(c) The experimentally observed absorption maxima and their intensities for hydroxybenzoic acids in ethanol and at $\mathrm{pH} 7$ (by L. Lang) and in water (by the present authors).

As mentioned earlier (vide method of calculation), it is assumed that for the PPP-CI procedure 


\begin{tabular}{|c|c|c|c|c|}
\hline \multirow{2}{*}{ Molecule } & \multicolumn{2}{|c|}{ Calculated values } & \multicolumn{2}{|c|}{ Experimental values } \\
\hline & $\begin{array}{l}\text { PPP-CI (Con- } \\
\text { ventional) } \\
\lambda_{\max }(\log \varepsilon) \\
(\mathrm{nm})\end{array}$ & $\begin{array}{l}\text { PPP-CI } \\
\text { (Modified) } \\
\lambda_{\max }(\log \varepsilon) \\
\quad(\mathrm{nm})\end{array}$ & $\begin{array}{l}\text { L. Lang } \\
(\text { Ref. [4]) } \\
\lambda_{\max }(\log \varepsilon) \\
(\mathrm{nm})\end{array}$ & $\begin{array}{l}\text { Present data } \\
\lambda_{\max }(\log \varepsilon) \\
(\mathrm{nm})\end{array}$ \\
\hline $\begin{array}{l}\text { p-Hydroxy- } \\
\text { benzoic acid }\end{array}$ & $\begin{array}{ll}271 & (2.10) \\
246 & (4.24) \\
203 & (3.91) \\
193 & (4.24)\end{array}$ & $\begin{array}{ll}274 & (1.80) \\
256 & (4.25) \\
209 & (3.73) \\
200 & (4.19)\end{array}$ & $\begin{aligned} * 284 & (1.05) \\
246 & (0.83) \\
208 & (0.692) \\
- & \end{aligned}$ & $\begin{array}{l}283(2.8) \\
244(3.8) \\
- \\
-\end{array}$ \\
\hline $\begin{array}{l}\text { m-Hydroxy- } \\
\text { benzoic acid }\end{array}$ & $\begin{array}{ll}280 & (3.27) \\
234 & (3.93) \\
206 & (4.49) \\
199 & (3.64)\end{array}$ & $\begin{array}{ll}289 & (3.27) \\
237 & (3.64) \\
217 & (4.44) \\
200 & (3.93)\end{array}$ & $\begin{array}{r}* 302(1.06) \\
290(0.14) \\
250(1.27) \\
208(1.10)\end{array}$ & $\begin{array}{ll}288 & (3.32) \\
235 & (3.78) \\
- & \\
200 & (4.01)\end{array}$ \\
\hline $\begin{array}{l}\text { o-Hydroxy- } \\
\text { benzoic acid }\end{array}$ & $\begin{array}{ll}279 & (3.27) \\
239 & (4.01) \\
208 & (4.19) \\
198 & (4.01)\end{array}$ & $\begin{array}{ll}304 & (3.61) \\
248 & (3.27) \\
218 & (4.35) \\
211 & (3.40)\end{array}$ & $\begin{array}{r}+325(0.84) \\
235(0.70) \\
214(0.82) \\
205(0.62)\end{array}$ & $\begin{array}{ll}299 & (2.87) \\
233 & (3.08) \\
- & \\
204 & (3.9)\end{array}$ \\
\hline
\end{tabular}

Table 5. Electronic spectral data (theoretical and experimental) for Hydroxy benzoic acids.

* at $\mathrm{pH} 7$, in $1: 1$ phosphate buffer/Methanol, + in ethanol. (conventional as well as modified) that the $-\mathrm{COOH}$ group is $100 \%$ ionised. This of course is a valid assumption, as there is a fair agreement between the theoretical and experimental data. However, in both the experimental results, all the theoretical peaks are not well reproduced. In water, some of the peaks are out of scale, hence not atteinpled to record. A reasonable assignment of the absorption bands observed for the three isomeric hydroxybenzoic acids, based on our PPP-CI study is given below.

The electronic absorption spectra of p-hydroxybenzoic acid (at $\mathrm{pH} 7$ in $1: 1$ phosphate buffer/ methanol) consists chiefly three bands at 284, 246 and $208 \mathrm{~nm}$. The configuration interaction study assigns the band at $284 \mathrm{~nm}$ to be due to a transition involving bonding molecular orbital consisting mainly the phenolic part $\left({ }_{1} \pi\right)$ and the antibonding orbital, made up of the carboxylic part of the molecule $\left({ }_{2} \pi^{*}\right)$. The band at $246 \mathrm{~nm}$ may be due to transitions between:

(1) the bonding orbital consisting mainly of the phenyl part of the molecule $\left.{ }_{3} \pi\right)$ and ${ }_{2} \pi^{*}$,

(2) the ${ }_{1} \pi$ and the antibonding orbital built up mainly from the phenolic part of the molecule $\left({ }_{1} \pi^{*}\right)$ and ${ }_{2} \pi^{*} ;\left({ }_{1} \pi^{*},{ }_{2} \pi^{*} \leftarrow{ }_{1} \pi\right)$. The band at $208 \mathrm{~nm}$ involves two transitions names ${ }_{2} \pi^{*} \leftarrow{ }_{1} \pi$ and ${ }_{3} \pi^{*} \leftarrow{ }_{1} \pi$.

The absorption spectrum of the meta-isomer also gives three bands centered at 290,250 and $208 \mathrm{~nm}$ in the same medium as the para-isomer. These bands appear to suffer a slight red-shift from the para- isomer. The assignments of the first two bands are akin to those of para-isomer. However the low energy one at $302 \mathrm{~nm}$ may be due to a charge transfer band. The band at $208 \mathrm{~nm}$ differs from that of para- and is given an assignment involving mainly the transitions ${ }_{1} \pi^{*} \leftarrow{ }_{1} \pi$ and ${ }_{2} \pi^{*}-{ }_{3} \pi$.

The absorption spectrum of the ortho isomer is quite interesting and useful correlations based on the spectral results are available in the literature. The ortho-isomer also gives chiefly 3 bands centered at 325,235 and $205 \mathrm{~nm}$. There is a very large red shift for the lower energy band in comparison with the other two isomers. The observed red-shift may be mainly due to the perturbation of the $-\mathrm{OH}$ group, due to the intramolecular hydrogen bonding, the effect of which is spread over the entire molecule [27]. In the ${ }_{2} \pi^{*} \leftarrow{ }_{1} \pi$ transition, the excited state gets more stabilised and thus involving a shift to longer wave lengths. An identical band is present in the ortho-nitrophenol [17]. The assignments of these bands are similar to those in the other two isomers, however the 205 band arises due to ${ }_{1} \pi^{*} \leftarrow{ }_{1} \pi$ and ${ }_{2} \pi^{*} \leftarrow \pi_{2}$. The $214 \mathrm{~nm}$ band requires further study.

Thus in the electronic spectra of the three isomeric hydroxybenzoic acids there is an overall tendency for red shift from para through meta to ortho.

Thus from this theoretical study of hydroxybenzoic acids and their basic compounds it can be concluded that the electronic distribution and therefore the reactivity chiefly depends on the nature of the $-\mathrm{COOH}$ group. The orientation and substituent 
effects of the $-\mathrm{COOH}$ and $-\mathrm{COO}^{(-)}$groups are evidently different. However, the observed electronic absorption spectra of the hydroxybenzoic acids do not change drastically even if the molecule assumed to be is completely ionised and one carries out the calculations for the resultant hydroxybenzoate ions involving a less tedious procedure.

[1] (a) J. Catalan and J. I. Fernandez-Alonso, J. Mol. Struct. 27, 59 (1975); (b) J. Catalan and J. I. Fernandez-Alonso, Experimentia Suppl. 23, 177 (1976); (c) J. Catalan and F. Thomas, Adv. Mol. Relaxation Process 8, 87 (1976).

[2] G. E. Dunn and F. Kung, Can. J. Chem. 44, 1261 (1966).

[3] A. Cammarato and K. S. Rogers, J. Med. Chem. 14, 269 (1971)

[4] L. Lang, Absorption Spectra in the U.V. and Visible region, Akademia Kiado, Budapest Vol. XI, 1966.

[5] (a) J. C. Dearden and F. W. Forbes, Can. J. Chem. 38, 1837, 1294 (1960); (b) (b) F. W. Forbes, A. R. Knight, and D. L. Coffen, Can. J. Chem. 38, 728 (1960).

[6] I. Danihel and J. Kutham, Collection Czechoslov. Chem. Commun. 45, 2201 (1980).

[7] (a) J. A. Pople, Proc. Phys. Soc. London Ser. A, 69, 81 (1955); (b) R. Pariser and R. G. Parr, J. Chem. Phys. 89, 4253 (1967)

[8] M. D. Gordon and J. F. Neumer, J. Phys. Chem. 78, 1868 (1974)

[9] K. P. Krishnan Namboodiri, S. Viswanathan, R. Ganesan, and V. C. Jyothi Bhasu, J. Comput. Chem. 2, 392 (1981).

[10] K. P. Krishnan Namboodiri, S. Viswanathan, and V. C. Jyothi Bhasu, Monat. Chem. (in press).

[11] R. D. Topsom, Prog. Phys. Org. Chem. 12 (1976).

[12] C. K. Ingold, Structure and Mechanisms in Organic Chemistry, 2nd Edition, Cornell University Press, Ithaca 1969.

\section{Acknowledgements}

One of the authors (KPKN) wishes to thank the Department of Inorganic and Physical Chemistry, Indian Institute of Science, Bangalore, where part of this work was carried out, and also CSIR, New Delhi, for financial support.

[13] (a) K. Nishimoto and L. S. Forster, Theor. Chim. Acta. 4, 155 (1966); (b) M. L. Baily, Theor. Chim Acta. 13, 56 (1969); (c) I. Danihel and J. Kuthan, Collection Czechoslov. Chem. Commun. 44, 873 (1979).

[14] J. A. Pople and M. Gordon, J. Amer. Chem. Soc. 91, 4253 (1969).

[15] R. T. C. Brownlee and R. W. Taft, J. Amer. Chem. Soc. 92, 7007 (1970).

[16] L. Radom and J. A. Pople, M.T.P. International Rev. Science 1, 71 (1972)

[17] S. Kang and Moon-Hae Cho, Int. J. Quant. Chem. Symposia 7, 319 (1973).

[18] A. Pross and L. Radom, Prog. Phys. Org. Chem. 13, 1 (1981).

[19] W. J. Hehre, L. Radom, and J. A. Pople, J. Amer. Chem. Soc. 94, 1496 (1972)

[20] S. W. Dietrich, E. C. Jorgensen, P. A. Kollman, and S. Roothenberg, J. Amer. Chem. Soc. 98, 8310 (1976).

[21] C. M. Moser, J. Chem. Soc. Part 2, 1073 (1953).

[22] J. A. Pople and D. L. Beveridge, Approximate Molecular Orbital Theory, McGraw-Hill, New York 1970, Appendix.

[23] K. Nishimoto and L. S. Forster, Theor. Chim. Acta 3, 407 (1965).

[24] K. Nishimoto and N. Mataga, Z. Phys. Chem. 12, 335 (1957).

[25] M. J. S. Dewar and T. Morita, J. Amer. Chem. Soc. 91, $796(1969)$.

[26] A. I. Vogel, A Text Book of Practical Chemistry, London 1968, p. 775.

[27] S. Patai, The Chemistry of Hydroxyl Group, Part I, Interscience, London 1971, p. 352. 